\title{
Editorial Office Updates
}

Phillip Lupo, MLIS, Marjorie A. Bowman, MD, MPA, and

Anne Victoria Neale, PhD, MPH (J Am Board Fam Med 2011;24:224-225.)

\section{Journal of the American Board of Family Medicine Editorial Board Member Appointed Vice Dean of Medical Education}

The Fournal of the American Board of Family Medicine $(\mathcal{A} A B F M)$ would like to take this opportunity to congratulate editorial board member Dr. Maryjean Schenk, who has been appointed Vice Dean of Medical Education at Wayne State University School of Medicine, Detroit, MI. Dr. Schenk's main responsibilities include overseeing and guiding medical student education and residency programs in the 21 st century.

Dr. Schenk's previous position was Chair of the Department of Family Medicine and Public Health Sciences, home of the $7 A B F M$ editorial office, where she was instrumental in getting the department nationally ranked in the top ten by National Institutes of Health funding.

Congratulations, Dr. Schenk, on your achievement.

\section{Facebook and Twitter}

The $7 A B F M$ recently added Facebook and Twitter at the article level to its canon of supported social bookmarking sites. Now, from any article, readers can share what they are reading with friends and colleagues with a click of a button. Social bookmarking applications can be found in the right column of the article. Along with Facebook and Twitter, the $7 A B F M$ also supports Citeulike, Complore, Connotea, Delicious, Digg, Reddit, and Technorait.

\section{Call for Papers for "Teams in Primary Care" Theme Issue}

The $7 A B F M$ is pleased to announce a call for papers for a theme issue on "Teams in Primary Care." The next phase of high-quality medicine counts on teams of care. Teams are not new, yet clearly we

Conflict of interest: The authors are editors and staff of the JABFM.

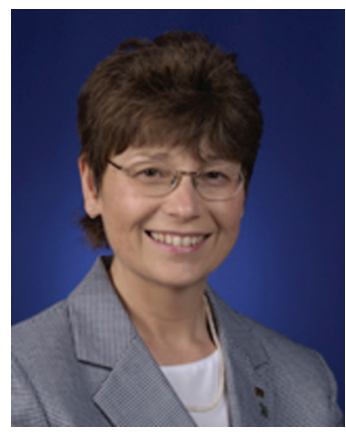

Maryjean Schenk, MD, MPH, MS

need new thinking about teams for our current and future models of care.

Thus, we encourage articles that report the great, the good, the bad, and the ugly. The big, grand schemes, and the little ones that make a difference. Every day, health care providers are making changes, whether voluntarily or forced by circumstances that change the mix and dynamics of teams and our production of best care. What works? How do we translate our knowledge of behavior change to this group level? How do teams function best? How can teams be managed or rewarded to maximize efficiency? What is the best mix of team members-by training, experience, or even personality? How do interdisciplinary teams work? How can teams grow and learn in place? How many patients should teams care for? What roles do patients play on teams? How does technology fit with team functioning? How do teams improve communication? We are also interested in theories of teams in primary care, with an eye toward both the past and the future.

We invite articles that report interventions and use a variety of well-accepted as well as innovative research methodologies. Short commentaries are welcomed from physicians who have experienced several types of teams and can provide insight for others who are considering changes.

The question list is long, but the needs are great. We look forward to wonderful new ideas and evidence for our next iteration of teams for 
health care. Submit your articles via Rapid Review on the $7 A B F M$ website (www.jabfm.org). Please note in your cover letter that you are submitting your manuscript for consideration for publication in the "Teams in Primary Care" theme issue. All submissions are peer reviewed and acceptance is not guaranteed. Direct questions to jabfm@med.wayne.edu. The deadline for submission is June 1, 2011.

Phillip Lupo, MLIS Anne Victoria Neale, $\mathrm{PhD}, \mathrm{MPH}$

Marjorie A. Bowman, MD, MPA 